\title{
DERECHO Y JUSTICIA, SEGÚN KELSEN
}

Alvaro Tord Velazco

Resumen

En el presente artículo el autor inicia con una breve reseña acerca de Hans Kelsen buscando a continuación resaltar las partes con más trascendencia de su Teoría Pura del Derecho como lo son, las ramas que implican contraposición en base a la justicia, las definiciones e implicancias de Derecho y Justicia, para luego hacer una distinción entre el Derecho Positivo y el Natural, y posteriormente comprender de una manera más cercana la diferencia entre estos y también exponer la Justicia, la Validez y la Eficacia como carácter coercitivo del Derecho.

Summary

The present article begins with a brief overview of Hans Kelsen seeking to highlight the most transcendental parts ofhis Puré Theory of Law as they are, the hranches involving opposition on the hasis ofjustice. definitions and implications of Law and Justice. To, then make a distinction hetween Positive and NaturaI Law, and then understand in a closest way the difference between them and also to expose the law, the validity and effectiveness as a coercive nature of law.

\section{Sommaire}

Dans cet article. I áuteur commence par un href aper<; u de Hans Kelsen dans le huí de mettre en évidence plusieurs parties de sa Théorie Puré du Droit tels qu 'iIs sont. les hranches qui impliquent le contraste en base á la justice, tes définilions et Ies implications du droit et de la justice, puis, se fasse une distinction entre le droit positif et naturel, et finalement, $s$ 'explique d'une faqon plus élroite sa difference et aussi s 'expose termes comme; la justice, la validité et I 'efficacité comme caractére coercitive du droit. 


\section{INTRODUCCIÓN}

Hans Kelsen nació en Praga en 1981 y murió en Berkeley, California, el 20 de Abril de 1973. Fue juez de la Suprema Corte de Austria y uno de los principales autores de la Constitución de Weimar de 1920.

También fue profesor de Filosofía del Derecho de la Universidad de Viena desde 1917. En 1929 obtuvo una cátedra en la Universidad de Colonia, la cual tuvo que abandonar en 1933 tras la ascensión del Nazismo. Luego de algunos años en la Universidad de Ginebra, enseñó en la Universidad de su ciudad natal en 1936.

El estallido de la Segunda Guerra Mundial lo llevó a refugiarse en los Estados Unidos en 1940. Allí ejerció la docencia en la Universidad de Harvard y luego en la de Berkeley hasta su muerte en 1973.

La Teoría Pura del Derecho (Reine Rechtslehre) fue su obra más importante, siendo La Teoría General del Derecho y del Estado, el tratado completo en que las ideas de dicha obra adquirieron acabada explicitación.

Su propósito fue presentar el Derecho como realidad distinta e independiente de otros órdenes normativos, como la moral. A partir de esa delimitación es que elabora su teoría de la ciencia jurídica.

Si bien el Derecho ha tenido un gran desarrollo desde la Teoría Pura del Derecho, la distinción en mención que hizo Kelsen, permite el entendimiento de que los dilemas que se presentan en las diversas ramas del Derecho, a todos los niveles, usualmente implican contraposiciones entre tesis que se apoyan en alguna concepción de lo "justo" y de aquellas que optan por la seguridad jurídica. De ahí la importancia de hacer una revisión de esta distinción y de otras conexas y sus consecuencias en la práctica jurídica.

\section{IL DERECHO V JUSTICIA}

Esta distinción constituye la piedra angular de la cual parte toda la Teoría Pura del Derecho. No solo por el lugar en el cual se encuentra dentro de su obra, sino porque en la medida que la misma pretende definir el Derecho, esta tarea debe comprender -en primer lugar- distinguirlo de la justicia, la idea que se le asocia mayormente. anhelo social:

Para Kelsen el Derecho es un orden de conducta humana y más bien la justicia es un

"La aspiración a la justicia es el eterno anhelo humano de felicidad. El individuo aislado no puede, en cuanto tal, encontrar la felicidad, y por ello la busca en la sociedad. Justicia es felicidad social." ${ }^{1}$

Kelsen, al igual que Bentham y Austin, también asocia la idea de justicia con la felicidad: La justicia es felicidad para todos. Sin embargo, Kelsen considera que la felicidad individual, entendida como la satisfacción de todos los intereses que una persona posee, en cierto momento entra en conflicto con la felicidad de otro individuo. 
Por esta razón, Kelsen creía que un orden social no podía asegurar la felicidad, sino solo en sentido colectivo, esto es, la satisfacción de ciertas necesidades que el legislador reconoce como dignas de ser satisfechas.

Sin embargo, ¿qué necesidades son dignas de ser satisfechas y, sobre todo, cual es el orden jerárquico que les corresponde? Para Kelsen esta respuesta no podía ser resuelta mediante un conocimiento racional, científico, dado que implicaba un juicio de valor de carácter subjetivo, variable de acuerdo a la idiosincrasia de cada individuo.

Así, en la medida que dichas necesidades y la jerarquía de las mismas no serán las mismas para un creyente, un ateo, un conservador, un liberal o un comunista, las discusiones en tomo a cuál valor debe primar, dependería de una deliberación política y no jurídica.

En ese sentido, para Kelsen la idea de lo justo no puede ser científicamente liquidada, toda vez que se trata de un asunto valorativo, que corresponde más al ámbito político que al jurídico. Por ello, al igual que los sistemas políticos como el Liberalismo, Comunismo o Fascismo, no dejan de serlo por los justos o injustos que puedan parecer desde cierto punto de vista, el Derecho no dejaba de serlo aunque sea parte de un sistema político calificado como injusto:

"La consecuencia de adoptar semejante definición sería que los ordenamientos sociales que existen en Rusia, Italia y Alemania no podrían ser ya considerados como jurídicos, a pesar de tener en común con el orden social de los Estados democrático-capitalistas, elementos muy importantes. El concepto mencionado anteriormente -defendido en obras recientes de filosofía del derecho- revela también hasta que punto una tendencia política puede influir sobre la definición del derecho. El concepto del derecho se hace entonces coincidir con un ideal específico de justicia, a saber, el de la democracia y el liberalismo. Desde el punto de vista de la ciencia, libre de toda clase de juicios de valor moral o políticos, la democracia y el liberalismo son únicamente dos principios posibles de organización social, lo mismo que la autocracia y el socialismo. No hay ninguna razón científica por la que el concepto del derecho tuviera que definirse de tal modo que excluyese a las dos últimas clases de organización de la sociedad. (...) Hay ordenamientos jurídicos que, desde cierto punto de vista, son injustos. Derecho y Justicia son conceptos diferentes." ${ }^{2}$

En ese sentido "Toda ideología política tiene sus raíces en la voluntad, no en el conocimiento (...) brota de ciertos intereses (...) no existe la posibilidad de adoptar una decisión racional relativamente a valores opuestos. Es precisamente esta situación de donde surge un conflicto realmente trágico: el conflicto entre la verdad, como principio fundamental de la ciencia, y la justicia, como supremo desiderátum de la política. ${ }^{3}$

Cuando Kelsen hizo estas afirmaciones se estaba dando la Segunda Guerra Mundial, momento en el cual era políticamente inaceptable afirmar que el Derecho

$2 \quad$ Ibid.Págs. 5 y 6.

$3 \quad$ Ibid. Pág. IX. 
Nazi era Derecho. En ese sentido, el propio Kelsen reconoció que la Teoría Pura del Derecho nació en un momento inoportuno:

"El ideal de una ciencia objetiva del derecho y del Estado, libre de todas las ideologías políticas, tiene mayores posibilidades de ser aceptada en un periodo de equilibro social. Parece, pues, que una teoría pura del derecho es inoportuna en la actualidad $(, . .)^{4 \prime \prime}$

Ese carácter "inoportuno" se debe a que la teoría de Kelsen define el carácter instrumental del Derecho: la idea de justicia como previa a la existencia del Derecho y que este como mecanismo para que dicha idea se haga efectiva en la sociedad. Para Kelsen Justicia es a lo que queremos llegar mediante el Derecho.

Como es sabido, esta separación entre Derecho como disciplina científica y justicia como concepto político generó una serie de críticas que señalaban que separar el Derecho de la Justicia implicaba aceptar la idea de que el Derecho podía ser injusto.

Sin embargo, Kelsen respondió a estas críticas señalando que la idea de que el Derecho debía ser justo no requería de explicación alguna, ya que era obvia; lo que no era obvio era que el derecho como ciencia no era capaz de ocuparse de la definición de la Justicia, toda vez que Derecho no equivale a Política:

"La tendencia a identificar derecho y justicia es la tendencia a justificar un orden social dado. No se trata de una tendencia científica, sino política. De acuerdo con ella, el esfuerzo de tratar el derecho y la justicia como problemas diferentes despierta la sospecha de que se trata de repudiar, al mismo tiempo, la exigencia de que el derecho positivo sea justo. Tal exigencia es evidente por sí misma; pero lo que en realidad significa es una cuestión diversa. Una teoría pura del derecho de ningún modo se opone a la exigencia de un derecho justo cuando se declara a sí misma incompetente para resolver la cuestión de si un determinado derecho es justo o no, o el problema acerca de cuál sea el elemento esencial de la justicia. Una teoría pura del derecho -en cuanto cienciano puede contestar esa pregunta, en virtud de que es imposible en absoluto responder a ella científicamente. ${ }^{\prime 5}$

La distinción que realiza Kelsen del Derecho y de la Justicia es fundamental para entender el fundamento del Derecho Positivo y su diferencia con el Derecho Natural.

\section{DERECHO NATURAL Y DERECHO POSITIVO}

La doctrina del Derecho Natural o Iusnaturalismo se puede definir como el pensamiento jurídico que concibe que la ley para que sea tal, debe ser conforme con la justicia $^{6}$. Sostiene esta doctrina que hay una ordenación de las relaciones humanas 
diferente del derecho positivo, superior a este y absolutamente válida y justa, en cuanto oriunda de la naturaleza, de la razón humana o de la voluntad de Dios ${ }^{7}$.

En palabras de Blaekstone, el hombre "ha establecido únicamente aquellas leyes fundadas en las relaciones de justicia que existían en la naturaleza de las cosas antes del establecimiento de cualquier precepto positivo. ${ }^{8}$.

Una formulación más reciente de esta doctrina la ofrece Gustav Radbruch: "Cuando una ley niega conscientemente la voluntad de la justicia, por ejemplo, cuando concede arbitrariamente o rechaza los derechos del hombre, adolece de invalidez (...) los juristas también deben tener el valor de negarle el carácter jurídico" ${ }^{9}$

Para Kelsen, el problema principal de esta doctrina jurídica consistía en que ninguna de sus numerosas teorías logró definir con éxito el contenido de ese orden justo, es decir, con la exactitud de una ciencia; todas se basan en fórmulas vacías como "a cada quien lo suyo" o "tautologías desprovistas de significado como el imperativo categórico kantiano"10.

Si solo fuera válido el Derecho que es justo, la justicia debería ser algo reconocible por todos, pero no lo es. Y si lo es, ¿por qué los seguidores del Derecho Natural tienen nociones tan disímiles sobre lo que es el Derecho Natural? Para Kant (y en general para todos los iusnaturalistas modernos) la libertad es natural; pero para Aristóteles también lo era la esclavitud. Para Locke la propiedad privada era natural, no así para los utopistas socialistas".

Por otra parte, afirmar que sólo es Derecho el que es justo, tiene el problema del punto de vista de quien hace el juicio de valor. Kelsen pone de ejemplo la propiedad privada que, según los iusnaturalistas, es un derecho natural. Consecuentemente un orden jurídico como el de los países comunistas que no la garantiza, no podría considerarse Derecho ${ }^{12}$.

Entonces, si la distinción entro lo justo y lo injusto no es universal, ¿A quién corresponde establecerla? ¿A quienes detentan el poder? Esta respuesta no tiene sentido, puesto que la idea de justicia surge justamente para controlar el poder. Por ello justicia no puede equivaler a poder.

La definición de justicia tampoco puede ser algo que se deje al arbitrio de cada persona, ya que se perdería algo fundamental en el Derecho que es la certeza: si todos pueden decidir lo que es la justicia, los gobernantes no podrían objetar nada y la convivencia civil organizada quedaría totalmente destruida ${ }^{11}$.

Sin duda, toda sociedad busca que su Derecho sea justo, pero ello no equivale a decir que el Derecho es Justicia. Justicia es la idea política y moral que los individuos tenemos respecto de cómo debe estar organizada la sociedad, pero ello varia de acuerdo a la sociedad donde nos encontremos.

Inclusive, dentro de una misma sociedad, puede haber distintos puntos de vista acerca de la Justicia y el Derecho es el reflejo de esa discusión. Pero el Derecho no es la discusión, es el producto de la misma:

\begin{tabular}{|c|c|}
\hline 8 & $\begin{array}{l}\text { KELSEIN. Op plit. Pág. y. } \\
\text { Comentarios de las leyes de Inglaterra, párrafos } 36 \text { y 39. En KELSEN. Op. Cit. Pág. } 10 .\end{array}$ \\
\hline $\begin{array}{l}\circ \\
9\end{array}$ & $\begin{array}{l}\text { Rechtsphilosophie, } 4^{\text {a }} \text { Edición, 1950. Pág. 336. En: BOBBIO, Nolberto. Op. Cit. Pág. } 40 . \\
\text { KELSEN. Op. Cit. Pág. } 11 \text {. }\end{array}$ \\
\hline 10 & \\
\hline 11 & BOBBIO. Op. Cit. Pág. 41. \\
\hline 12 & KELSEN. Op. Cit. Pág. 12. \\
\hline 13 & BOBBiO. Op. Cit. Pág. 42. \\
\hline
\end{tabular}


"El Derecho Positivo es siempre el derecho de una comunidad determinada: el derecho de los Estados Unidos, el de Francia, el mexicano, el internacional. Realizar una exposición científica de los ordenes jurídicos particulares constitutivos de las correspondientes comunidades jurídicas, es el propósito de la teoría general de derecho"14

Kelsen, al igual que Austin, considera que la definición del Derecho no debe ser de carácter deductivo (es decir, a partir de la naturaleza o de la sociedad) sino inductivo, es decir, a partir del análisis de los diversos sistemas jurídicos reconocidos históricamente como tales:

"La orientación de la teoría jurídica pura es, en principio, la misma de la Ilamada jurisprudencia analítica. A semejanza de lo que hace John Austin en su famoso libro Lectures on Jurisprudence, la teoría pura del derecho trata de obtener sus resultados exclusivamente a través de un análisis del derecho positivo. ${ }^{15 "}$

Pero a diferencia de Austin, Kelsen pensaba que la finalidad del Derecho no era brindar la "mayor felicidad para el mayor numero de personas" (principio del Utilitarismo), sino que este debía de "asegurar la felicidad en sentido colectivo, esto es, la satisfacción de ciertas necesidades, reconocidas por la autoridad social, el legislador, como dignas de ser satisfechas"16

El Derecho debe asegurar dicha concepción de felicidad colectiva, pero la concepción misma, según Kelsen, es tarea de la Política porque no se trata de un asunto racional, científico, sino de índole política, emocional, de pugna de valores. Por ello, la decisión de optar por el valor de libertad, como el caso del liberalismo, o el valor igualdad como el comunismo, no es un asunto jurídico, sino político.

Entonces, una vez trazada la línea que separa el Derecho de la Política y una vez identificadas las similitudes entre los ordenamientos de países con opciones políticas diametralmente opuestas, Kelsen deduce que el Derecho nos es mas que una técnica de organización social coactiva, que sirve de herramienta para plasmar el orden político que la sociedad ha adoptado.

\section{Y DERECHO COMO TÉCNICA DE ORGANIZACIÓN}

\section{SOCIAL COACTIVA} definición:

La "Teoría General del Derecho y del Estado" comienza con la siguiente

"El derecho es un orden de la conducta humana. Un "orden" es un conjunto de normas." ${ }^{17}$

$\begin{array}{lll}14 & \text { KELSEN. Op. OL Pág. V. } \\ 15 & \text { 7óid } & \text { Pág. VIII. } \\ 16 & \text { 7óid. } & \text { Pág. 7. } \\ 17 & \text { 7óid. } & \text { Pág. 3. }\end{array}$


El orden jurídico determina como debe ser la conducta de los hombres. Es un sistema de normas, un orden normativo. Pero ordenes normativos existen aparte de lo que históricamente denominamos Derecho. La religión, la moral, y otros fenómenos sociales también son sistemas u órdenes normativos, pero ¿Qué los diferencian del Derecho?

El Derecho es ante todo un orden social que provoca de cierta forma cierta conducta recíproca de los seres humanos, es decir, que se abstengan de realizar determinados actos que por alguna razón se consideran perjudiciales para la sociedad y que realicen otros que se consideran útiles para la misma ${ }^{18}$.

Kelsen distingue varios tipos de órdenes sociales según la forma en la cual se lleva a cabo la conducta social deseada. La primera distinción que realiza es la de órdenes sociales que inducen a los individuos a comportarse de cierta manera mediante una motivación directa o indirecta.

La motivación directa consiste en acatar una regla por su simple exigencia y no por evitar la sanción que acarrea su incumplimiento, dado que esta no existe. La motivación indirecta consiste en el principio de retribución por el cual se liga la conducta al orden establecido mediante sanciones o recompensas.

Una segunda clasificación es la de orden social que interpone sanciones trascendentes y orden social que interpone sanciones socialmente organizadas. En el primer caso, es una autoridad sobrehumana la que ejecuta la sanción, en el segundo es la sociedad misma.

Linalmente, Kelsen distingue los órdenes sociales entre los que establecen sanciones y los que establecen recompensas. Obviamente, la más utilizada es la técnica de la sanción, siendo la de la recompensa utilizada sólo en ámbitos privados.

Hechas estas distinciones, Kelsen señala que si limitamos nuestras investigaciones al Derecho Positivo y comparamos todos los ordenamientos sociales, pasados y presentes, a los que generalmente se les da el nombre de Derecho, descubriremos que tienen una característica común, que los órdenes sociales de otra clase nunca presentan: la coacción.

El Derecho, dice Kelsen, es un orden social cuyas sanciones están socialmente organizadas y consisten en privar ciertas libertades: vida, libertad, propiedad, etc. En la medida que estas privaciones son efectuadas contra la voluntad del sancionado, estas tienen el carácter de coercitivas. En ese sentido, el Derecho es un orden social coactivo $^{19}$.

Como tal. difiere de todos los demás órdenes sociales posibles en que establece castigos y no recompensas como sanciones y en ese sentido utiliza la técnica de la motivación indirecta y no la directa.

Para Kelsen, sólo esta definición del derecho hace posible entender porque definimos como "Derecho" al Derecho Babilónico, Romano, el de las tribus africanas $y$ el de los estados modernos. Aunque estos pueblos sean tan diversos desde el punto de vista temporal, espacial y cultural, todos tienen una técnica social que consiste en provocar la conducta socialmente deseada a través de la amenaza de una medida coercitiva que debe aplicarse en caso de un comportamiento contrario ${ }^{20}$.

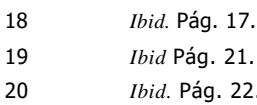


Al entender al Derecho como una técnica social de un orden coactivo, Kelsen lo distingue claramente de otros ordenes sociales como es la moral o la religión. A diferencia del Derecho, la sanción moral por el incumplimiento de normas éticas no está establecida por el orden moral o, por ultimo, no se halla socialmente organizada. Desde este punto de vista, la religión se encuentra más cerca del Derecho, pues el incumplimiento de sus normas sí acarrea castigos predeterminados. La diferencia entre el Derecho y la religión es que las sanciones de esta última son de carácter trascendente, en cambio las sanciones jurídicas no.

\section{Ü JUSTICIA. VALIDEZ Y EFICACIA}

Para Kelsen el carácter coercitivo del Derecho únicamente tiene importancia cuando forma parte del contenido de una norma jurídica ${ }^{21}$. Frente a cualquier norma jurídica podemos planteamos un triple orden de problemas: si es justa, si es válida y si es eficaz. Se trata de tres diferentes problemas ${ }^{22}$.

El problema de la justicia es la correspondencia entre el Derecho (las normas jurídicas) y los valores superiores que inspiran a una determinada sociedad. Para quien no crea en valores absolutos, el problema de la justicia equivale a preguntarse si las normas son aptas para realizar los valores históricos que inspiran a una sociedad.

Entonces, el problema de la justicia es plantear el problema de la correspondencia entre lo real y lo ideal, de lo que el Derecho debe ser, es decir, el problema deontológico del Derecho 23

El segundo problema es de la validez, que consiste en verificar la existencia de la norma mediante una operación empírica - racional que implica a su vez determinar que esta no haya sido derogada o anulada. Este es el problema ontológico del Derecho ${ }^{24}$.

Finalmente está el problema de la eficacia que consiste en saber si las normas son cumplidas. Esta investigación es de carácter histórico - social, diferenciándose del carácter filosófico-político en el caso de la justicia y en la exclusivamente jurídica en el caso de la validez. Este es el problema fenomenológico del Derecho. ${ }^{25}$

Estos tres criterios son independientes, puesto que una norma puede ser justa sin ser válida (como la libertad en una tiranía); válida sin ser justa (como la esclavitud en la Grecia antigua); válida sin ser eficaz (como la prohibición del alcohol en los EE.UU.); eficaz sin ser válida (como la costumbre no reconocida jurídicamente); justa sin ser eficaz (como los 10 mandamientos) y; eficaz sin ser justa (como la esclavitud en la Grecia antigua) ${ }^{26}$.

Cada problema es el objeto de tres disciplinas distintas: la Filosofía de la Justicia, la Teoría Pura del Derecho y la Sociología Jurídica:

\begin{tabular}{|c|c|}
\hline 21 & Ibid. Págs. 34-35. \\
\hline 22 & BOBBio. Op. Cit. \\
\hline 23 & IbiPá \\
\hline 24 & $I b i$ \\
\hline 25 & \\
\hline 26 & \\
\hline
\end{tabular}


"Casi toda la ciencia jurídica tradicional (...) confunde el problema de la esencia del derecho con lo que debiera ser, identificando el derecho con la justicia. Por otra parte, algunas teorías jurídicas tienden a ignorar la línea divisoria que separa la teoría de las normas jurídicas que regulan la conducta humana, de la ciencia que explica en forma causal el comportamiento real de los hombres, esto es, la sociología general (...) únicamente separando la teoría del derecho de la filosofía de la justicia y de la sociología, será posible establecer una ciencia jurídica específica". ${ }^{27}$

El positivismo nace en oposición del Derecho Natural que reduce la validez a la justicia. Para el positivismo el Derecho tiene como objeto analizar la validez, es decir, si estamos ante una norma jurídica existente, no justa.

Por su parte, serán las corrientes denominadas Realistas, las que no pondrán énfasis en la justicia ni en la validez de la norma, sino en su eficacia.

\section{MANIFESTACIONES DE LA DICOTOMÍA: \\ "JUSTICIA-VALIDEZ" EN EI, DERECHO POSITIVO}

La distinción entre Derecho y Justicia en la obra de Kelsen no es sólo una cuestión teórica, sino que permite entender el funcionamiento de los sistemas jurídicos, en los cuales esta dicotomía se manifestará en conflictos y dilemas en todos los niveles.

Por ejemplo, todas las normas que establecen plazos no tienen sustento moral alguno. Los plazos sirven para dar seguridad, no para defender algún valor moral. Incluso, la prescripción penal puede ser vista como inmoral, puesto que se exculpa al criminal por el paso del tiempo. Sin embargo, una sociedad sin prescripción sería impensable.

Y es que la seguridad, el orden, la paz social (que es aquello que está detrás de la noción de validez de Kelsen) son tan importantes como la justicia y los valores morales.

El caso paradigmático es el de la cosa juzgada, según la cual las decisiones jurisdiccionales de los órganos supremos del Poder Judicial (o de aquellos inferiores que no fueron debidamente impugnadas) ponen fin al conflicto de manera definitiva, a pesar que la decisión pueda ser contraria incluso a hechos científicos (un prueba de ADN por ejemplo que demuestre que la sentencia que adquirió cosa juzgada en un proceso de reconocimiento de paternidad, estaba científicamente equivocada).

Pero, por injusta que sea, nadie duda que la cosa juzgada es imprescindible en todo sistema jurídico pues, de no existir, los conflictos se perpetuarían hasta, teóricamente, el infinito, lo cual provocaría una inseguridad jurídica de tales proporciones que la convivencia humana sería simplemente imposible. ${ }^{28}$ 
Sin embargo, la relativización de la separación del Derecho de concepciones morales en tendencias post positivistas como el Constitucionalismo, han permitido la posibilidad de que la cosa juzgada pueda ser revisada por afectación de derechos constitucionales, por ejemplo ${ }^{29}$.

Otro ejemplo es el de la interpretación contractual. El método de interpretación literal -que es la técnica de interpretación según el cual es la letra estricta del contrato la que establece las situaciones jurídicas subjetivas de las partes tendrá como fundamentos nociones ligadas a la seguridad jurídica; en cambio otros métodos como la buena fe, se encuentran mas ligados a nociones de justicia entre las partes, que pueden ser sustentadas con argumentos éticos, económicos, etc.

A nivel constitucional, un caso típico del enfrentamiento entre justicia y seguridad jurídica es el de la desobediencia civil y la objeción de conciencia. De acuerdo a Rawls, la desobediencia civil es un acto ilegal, publico, no violento, de carácter político, realizado habitualmente para provocar un cambio en la legislación o en la política gubernamental- ${ }^{10}$.

El ejemplo clásico de objeción de conciencia es el de Rosa Louise Parks, una mujer norteamericana de ascendencia africana, quien se negó a ceder el asiento a un hombre de raza caucásica y moverse a la parte de atrás del autobús, como dictaba la ley de la época (1955) en el sur de los Estados Unidos. La acción concluyó con su encarcelamiento. En 1956, el caso de Parks llegó a la Corte Suprema de los Estados Unidos que declaró que la segregación en el transporte estaba en contra de la Constitución de ese país.

La objeción de conciencia es una especie de protesta hacia una norma, por ser considerada inconstitucional o contraria a los valores en que se funda la sociedad. No se apela a cuestiones de moralidad personal o religión, pero pueden coincidir. Se apela a la concepción común de justicia del orden político. Es una desobediencia a una norma, pero con fidelidad al ordenamiento (no es una revolución).

De alguna manera, es un medio de control de la constitución, pero a diferencia del Tribunal Constitucional (control concentrado) o del Poder Judicial (control difuso) este es particular y extralegal. De ahí que su permisión irreflexiva pueda significar una amenaza a la seguridad jurídica.

Algo parecido ocurre con la Objeción de Conciencia, que es el incumplimiento de una norma dirigida al objetante por motivos personales morales o religiosos $^{31}$. Es el caso de la negativa de testigos de Jehová a jurar bandera, la resistencia de una pacifista a hacer el servicio militar o de un soldado ante una orden injusta. La Objeción de Conciencia es un acto evidente (si es clandestino se llama Evasión de Conciencia, como lo era ayudar a esclavos fugitivos). Se diferencia de la Desobediencia Civil en que no se apela al sentido de justicia mayoritario, sino a convicciones personales.

Sin embargo, al igual que la Desobediencia Civil, su permisión irreflexiva puede llevar a que el sistema pierda autoridad, dejando el camino abierto para el

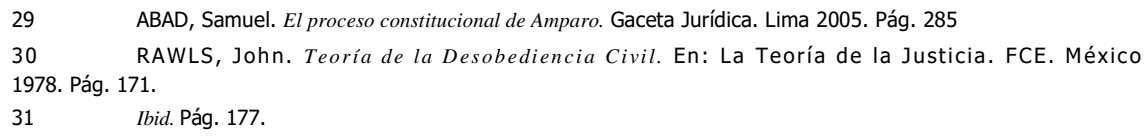


incumplimiento generalizado e injustificado. Aquí se sacrifica la seguridad por la justicia. Es curioso advertir que, al momento de tratar de resolver un conflicto, sea este patrimonial o no patrimonial. Constitucional o de rango normativo inferior, los problemas que surgen parecen ser, si se logra encontrar el "núcleo" dentro de los mismos, un mero eco o reflejo de aquellos que Kelsen advirtió al momento de realizar su distinción del Derecho y la Justicia en su Teoría Pura del Derecho. 
